Arqueología y Sociedad,

№ 20, 2009

\title{
CABEZAS DE ARCilla COMO SUSTITUTAS DE CABEZAS TROFEO DE NASCA*
}

\author{
Beatrix Hoffmann**
}

\section{Resumen}

Se caracteriza las denominadas "cabezas trofeo" nazca representadas en cerámicas, procedente de la costa sur del Perú, para proponer la posible función y significado que cumplió a partir de las representaciones iconográficas y comparaciones con ejemplos de otras partes mundo. El autor sugiere que las cabezas trofeo reales y las representaciones de tales cabezas fueron importantes en la cosmovisión; no era necesario utilizar los primeros para cumplir dichas funciones, sino se utilizó símbolos, replicas en arcilla y las pinturas correspondientes en contextos funerarios como sustitutos de los reales. Así, como en otras partes del mundo se muestra la complejidad y variabilidad de las ideas relacionadas, es difícil comprender cabalmente la función y significado de las cabezas trofeo nazca.

\section{Palabras clave}

Cabezas trofeo, iconografía, símbolos, sustitutos, variabilidad.

\begin{abstract}
The so called "heads are characterized trophy" be born represented in ceramics, proceeding from the south coast of Peru, to propose the possible function and meaning that fulfilled from the iconographic representations and comparisons with examples of other parts world. The author suggests that the heads trophy real and the representations of such heads were important in the world view; it was not necessary to use the first ones to fulfill the above mentioned functions, but symbols were used, you answer in clay and the corresponding paintings in funeral contexts like substitutes of the real ones. This way, since in other parts of the world there appears the complexity and changeability of the related ideas, the function is a difficult comprehension cabalmente and meaning of the heads trophy is born.
\end{abstract}

\section{Keywords}

Heads trophy, iconography, symbols, substitutes, changeability.

* Traducción de B. Hoffmann y J. Golte.

** Freie Universität Berlin. 
La cerámica nasquense con sus pinturas multicolores de temas variados es uno de los legados más impresionantes del Perú Antiguo. Ha sido fabricada en los valles de las costa surperuana, especialmente en el del Río Grande de Nasca, durante los siglos comprendidos entre el año 100 antes de nuestra Era y el 600. Muchas de estas vasijas han sido preservadas como ofrendas funerarias.

Un tema de la iconografía nasquense que ha sido discutido repetidas veces en relación directa con los hallazgos arqueológicos son las «cabezas trofeo», es decir cabezas humanas separadas del cuerpo. El que se las llame de esta forma se remonta a los trabajos de Max Uhle (1901) y resulta erróneo en cuanto a su función, ya que parecen haber tenido poca importancia como trofeos de guerra o de victoria, pero mantenemos el concepto porque es el que se utiliza comúnmente para designarlas.

Son dos los elementos que llaman la atención con estas cabezas. Primero, son un elemento frecuentemente pintado o representado en la cerámica; segundo: hasta el momento se ha encontrado una centena de cabezas trofeo reales en las investigaciones arqueológicas (Proulx, 1999: 81). Cabezas trofeo son documentadas en el Perú ya en el precerámico. En Asia, por ejemplo, se encontró tanto entierros de tales cabezas, como también entierros de cuerpos decapitados, que han sido fechados para el año 2000 antes de Cristo (Silverman, 1993: 218). En la iconografía aparecen ya antes y durante el Horizonte Temprano, así, por ejemplo, en los relieves de Cerro Sechín y en esculturas de piedra en Chavín (Silverman, 1993: 218). En los textiles Paracas aparecen como motivos tempranamente, mientras en la cerámica de esta cultura se las encuentra recién a partir de la fase 9 (Proulx,
1999: 79). Una verdadera inflación experimentó su representación en la cultura Nasca. Por lo visto en Nasca las tales cabezas ocupaban un lugar central en la vida y el imaginario nasquenses.

En la iconografía nasca las representaciones de cabezas trofeo son muy variadas. Aparte de la inexistencia de un cuerpo correspondiente tienen adicionalmente características que las identifican. Frecuentemente las pupilas de los ojos abiertos han sido puestas en el borde superior del ojo. Algunas representaciones muestran sangre que sale de las heridas de la cabeza cortada. Frecuentemente las bocas han sido marcadas con dos rayas verticales. En las cabezas trofeo reales la boca aparece cerrada con espinas o astillas de huarango ${ }^{1}$. Algunas de las representaciones también muestran una cinta o un cordel en la frente de la imagen. En las cabezas trofeo reales se halla frecuentemente un agujero taladrado en el hueso frontal, por el cual se pasó un cordón. Las cabezas trofeo no han sido representadas únicamente en forma naturalista, sino que encontramos una gama amplia de estilizaciones. Quizás la forma más abstracta sea su representación por medio de tres puntos en posición triangular. Tales representaciones se encuentra frecuentemente en las puntas de las plumas de seres emplumados, pero también aparecen como parte de vestimentas o de adornos en la cabeza de los personajes, u ocurren simplemente como bandas ornamentales.

Las representaciones pintadas se puede agrupar como sigue:

1. Cabezas trofeo como parafernalia. Los seres antropomorfos con antifaz que aparecen frecuentemente en la iconografía nasquense ${ }^{2}$, y también los compuestos antropo-zoomorfos, frecuentemente sostienen en una de sus manos una cabeza trofeo (fig. 1).

1 Esta práctica la conocemos también en los jíbaros, un grupo étnico que habita en la montaña, en la frontera entre el Perú y el Ecuador. Ellos han sido hasta mediados del siglo XX cazadores de cabezas. Las bocas de las cabezas reducidas, que elaboraron de las cabezas de sus enemigos, se cerraba con las espinas de la palmera chonta. (compárese Harner, 1984: 143ss).

2 Estos seres antropomorfos siempre muestran una máscara, una diadema y adornos en las orejas, llevan una cabeza trofeo en la mano derecha y en la otra un bastón. En la discusión iconográfica se les llama «seres míticos», algunas veces también «chamanes» (Proulx, 1999:79). Ambas interpretaciones son comprensibles, pero no comple- 


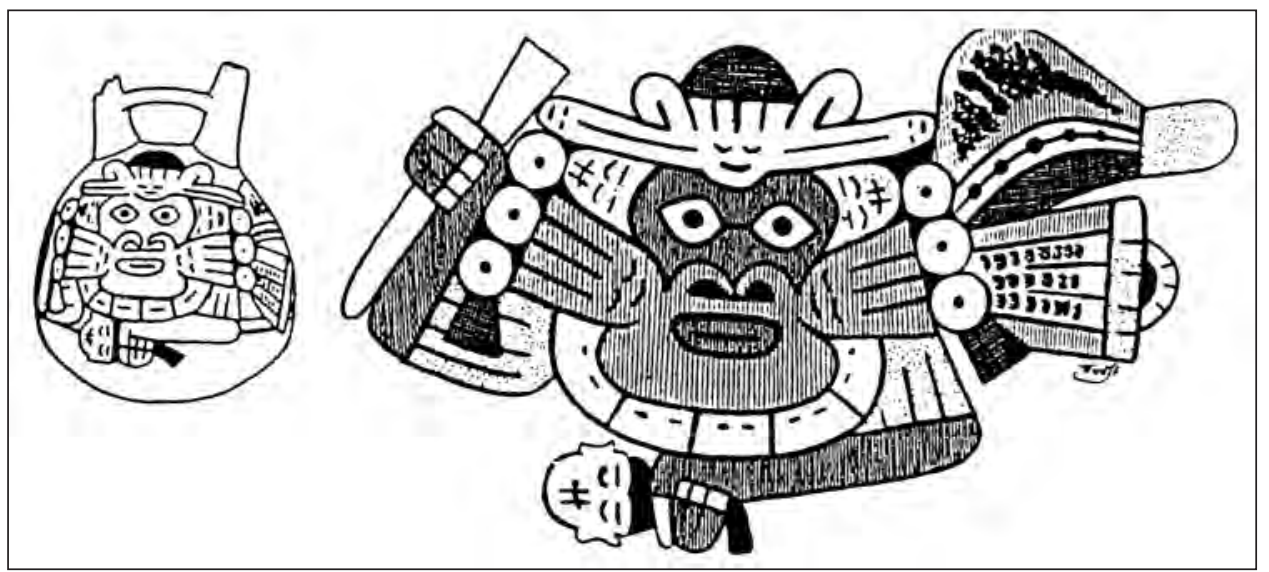

Figura 1

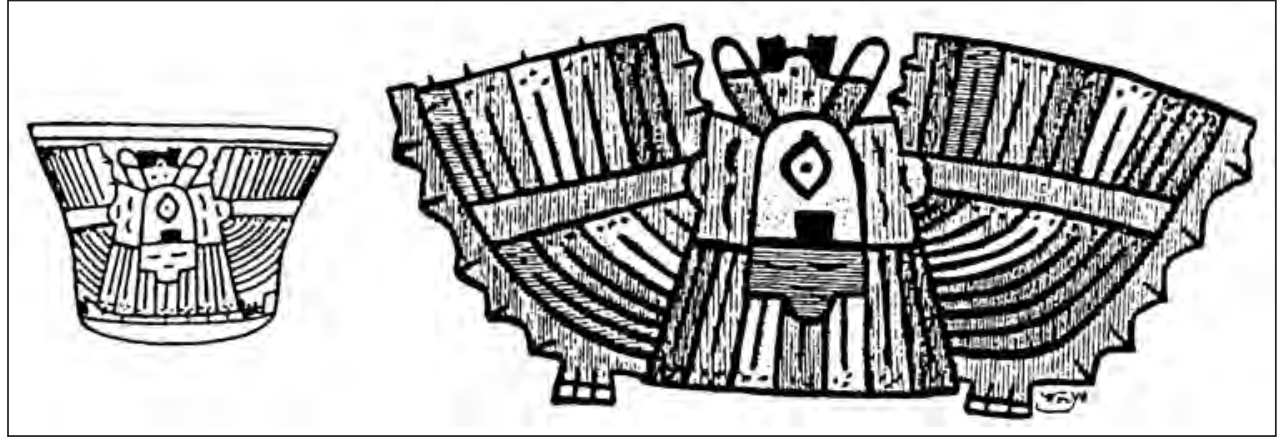

Figura 2

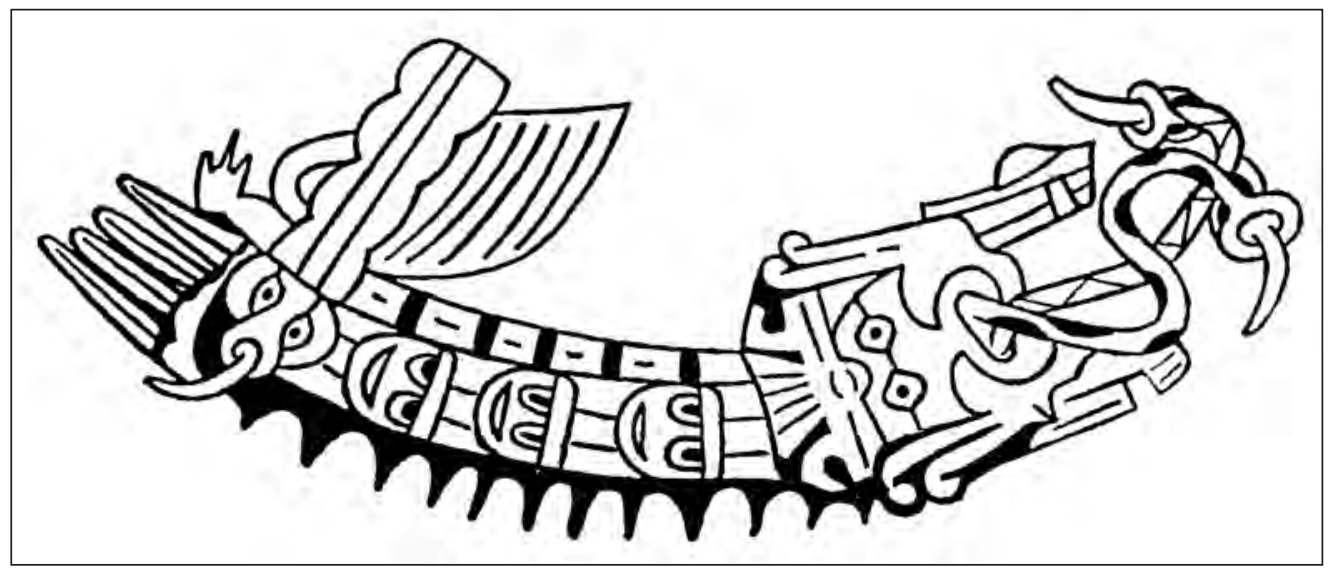

Figura 3 
2. Cabezas trofeo como elementos constitutivos de diadema o antifaz, o de vestimenta o plumaje. En esta forma se las encuentra en los seres de poder ya mencionados. En éstos aparecen menos estilizados y en cantidades mayores. Frecuentemente son sólo los tres puntos ya mencionados, especialmente en el plumaje de seres ornitomorfos. De vez en cuando la superficie del cuerpo secundario, que se ha acostumbrado a llamar signifer, muestra cabezas trofeo grandes (fig. 2).

$2^{\text {a }}$ Un subgrupo lo forman animales cuyo cuerpo está completamente cubierto por cabezas trofeo pintadas. Por lo general éstos son o culebras o gusanos, o aves (fig. 3).

3. Cabezas trofeo como elemento de decoración. Hay vasijas que están adornadas parcial -o completamente- con cabezas trofeo más o menos estilizadas. Éstas pueden aparecer de perfil o de frente, con sangre que emana del cuello, con o sin cordel en la frente. Además las caras pueden aparecer de un color o de colores diversos en una secuencia repetitiva. Del mismo modo, las tales cabezas son o todas puestas horizontalmente en la misma dirección o contrapuestas,

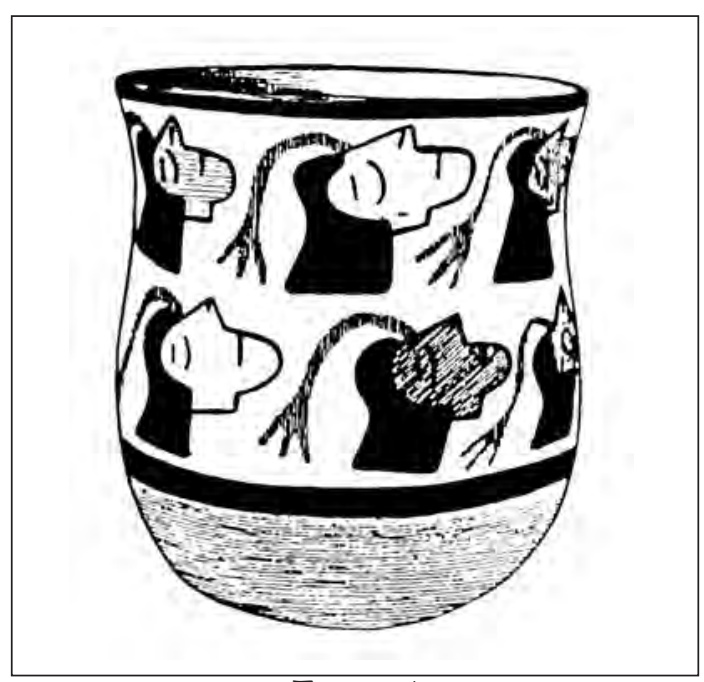

Figura 4 de manera que sólo cada segunda cabeza se halla en la misma posición (figs. 4 y 5).

Por la forma de las vasijas que representan una cabeza ${ }^{3}$ estas pueden subdividirse como sigue:

1. Vasijas de estribo: estas, en forma lenticulada, que representan una cabeza, son relativamente raras. Algunas veces tienen un solo pico, o dos unidos por un puente. Proulx (1968: 13) considera a las botellas de dos picos como de mayor prestigio, ya que muchas veces se encuentra uno sola en una tumba, y frecuentemente muestran escenas míticas (fig. 6).

2. Vasijas globulares: también relativamente raras son vasijas globulares sin gollete, que representan una cabeza (fig. 7).

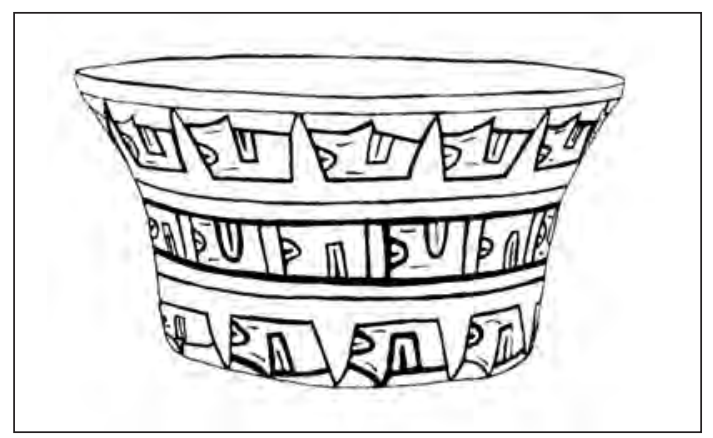

Figura 5

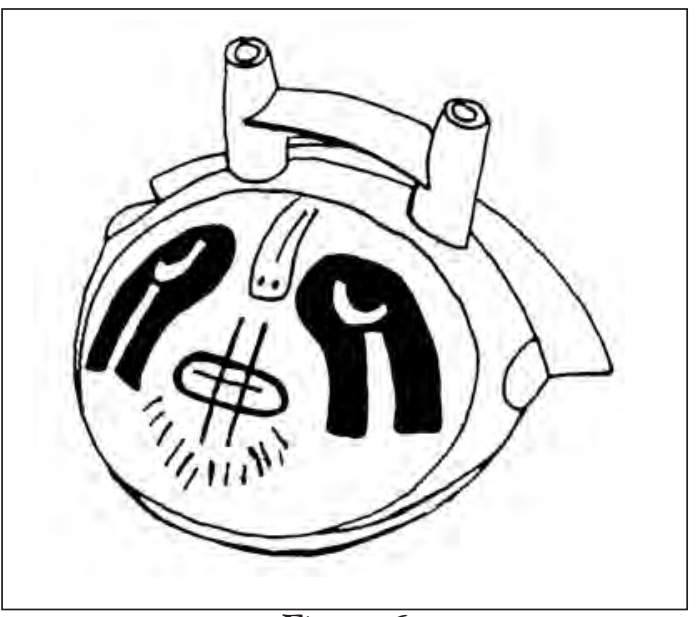

Figura 6

tamente convincentes. Es ésta la razón por la que evitamos verbalmente la identificación con las dos posiciones.

3 Esta clasificación no coincide en todos los puntos con la efectuada por Kroeber y Collier (1998: 94). Ellos diferencian cinco tipos. 


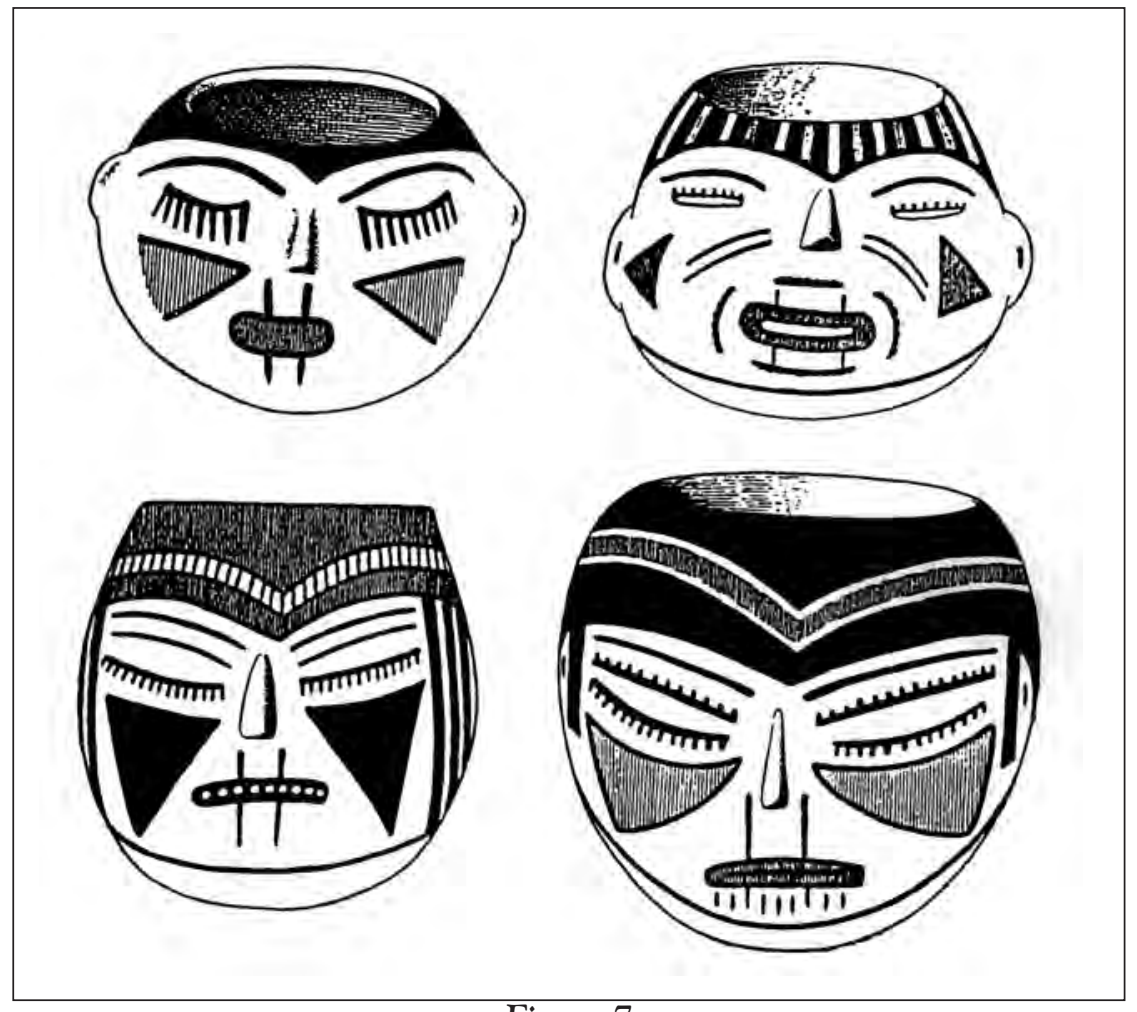

Figura 7

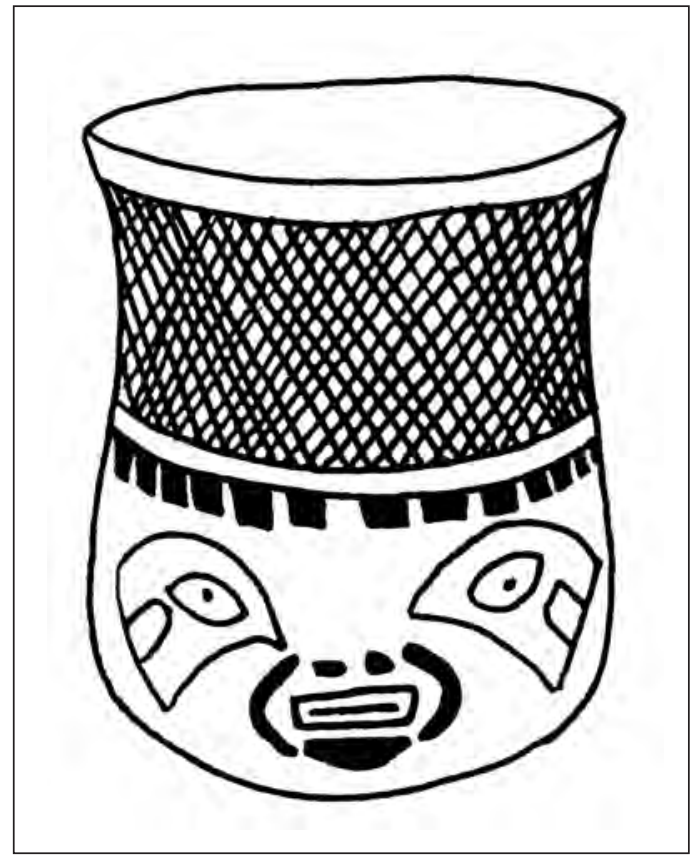

Figura 8
3. Vasos: la parte inferior de estos recipientes, que ocurren con bastante frecuencia, muestra una cara, en la parte superior aparece como un tocado o una banda circular, y es pintada con motivos diversos. Los vasos se dejan agrupar por su forma en dos categorías:

3a. Al primer grupo pertenecen vasos que tienen una pared vertical, cuyo perfil representaría una S muy tenue. En la fase 3 esta forma aparece con mayor frecuencia y se mantiene hasta las fases posteriores, en las cuales las paredes son casi verticales, de perfil recto y la altura crece marcadamente. En las primeras fases las bandas en la cabeza muestran casi sólo un motivo, mientras las de los posteriores están decoradas con dos o más bandas superpuestas con varios motivos.

3b. A este grupo pertenecen vasijas de las fases 3 a 7, en la parte que representa la cabeza son casi globulares y tienen un gollete en forma de embudo. El embudo esta decorado con va- 
rias bandas superpuestas que muestran decoraciones con figuras o motivos abstractos (figs. 8 y 9).

Las vasijas de forma lenticular con asa de estribo son modeladas con más semejanza con una cabeza humana ${ }^{4}$ y representan de manera inequívoca y clara cabezas trofeo. Normalmente presentan la boca sellada con espinas, el cordel y la posición característica de las pupilas. Algunas veces los ojos aparecen cerrados. Algunas vasijas muestran pintura roja, que representa sangre, en el cuello. Lo mismo vale para las vasijas globulares en ellas con más frecuencia deja de aparecer el cordel. Las cabezas en forma de vaso sólo raras veces muestran uno o varios de los rasgos típicos. Visiblemente en ellas la intención de decorar el gollete con una o varias bandas superpuestas se vuelve el punto de atención principal. Sin embargo, también ellas son representaciones de cabezas trofeo, ya que algunas muestran la posición típica de las pupilas o la boca cerrada con espinas. Una comparación con cabezas trofeo reales muestra que también estas pueden mostrar variantes en la preparación.

Casi todas las vasijas de cabeza trofeo muestran pintura facial ${ }^{5}$. Los diversos motivos aparecen por un lado sobre las mejillas y por otro en el borde de los ojos. El motivo mas frecuente es el «ojo de halcón», que se parece a la marcación de la cabeza del halcón ${ }^{6}$. Al lado de éste se encuentran círculos, escaleras, rayas verticales (anchas, delgadas, simples o múltiples, de forma cóncava, algunas veces decorada internamente con otro motivo), bandas verticales, triángulos y bandas en forma de onda sinuosa. Entre los colores domina el rojo y el negro, el último especialmente en los de motivo de halcón. Los motivos de los tatuajes igualmente se encuentran en las representaciones plásticas de las vasijas, si bien en algunas no aparecen. En los motivos de «tatuaje» de las vasijas de cabeza trofeo no se puede percibir relación ni con la forma de la cara, ni con la decoración de las bandas del tocado. La única excepción a esta regla la discutiremos más abajo. También las pinturas facial en esculturas de cuerpo completo no deja percibir una tal relación para con la figura en conjunto?.

La decoración de las bandas del tocado en las vasijas de cabeza trofeo, especialmente en las fases tempranas, muestran peinados, diademas o tocados, así como de una u otra forma también aparecen en los hallazgos arqueológicos reales. Fá-

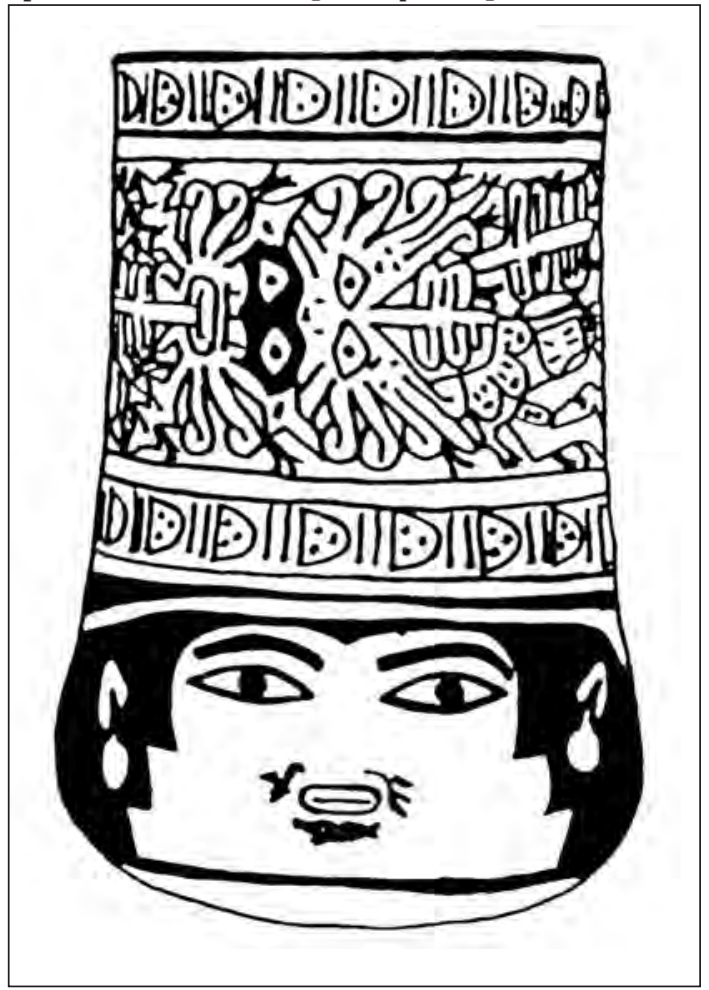

\section{Figura 9}

4 En ningún caso las representaciones alcanzan el realismo mochica.

5 Tatuajes y pintura facial son y eran habituales entre muchas etnias en América del Sur especialmente entre los pueblos de la Amazonía. Se aplica esta pintura de acuerdo a las circunstancias y las predilecciones de las personas. En varias momias provenientes de la costa los tatuajes son claramente distinguibles. Es muy probable que las vasijas muestren pinturas y tatuajes que efectivamente eran las utilizadas por la población.

6 Falco sparveridus.

7 Blasco Bosqued y Ramos Gómez (1986, lam. VI) tratan de establecer una correlación según la cual el motivo de los ojos de halcón sería una pintura facial de guerra, sin embargo el material no sostiene esta opinión. 


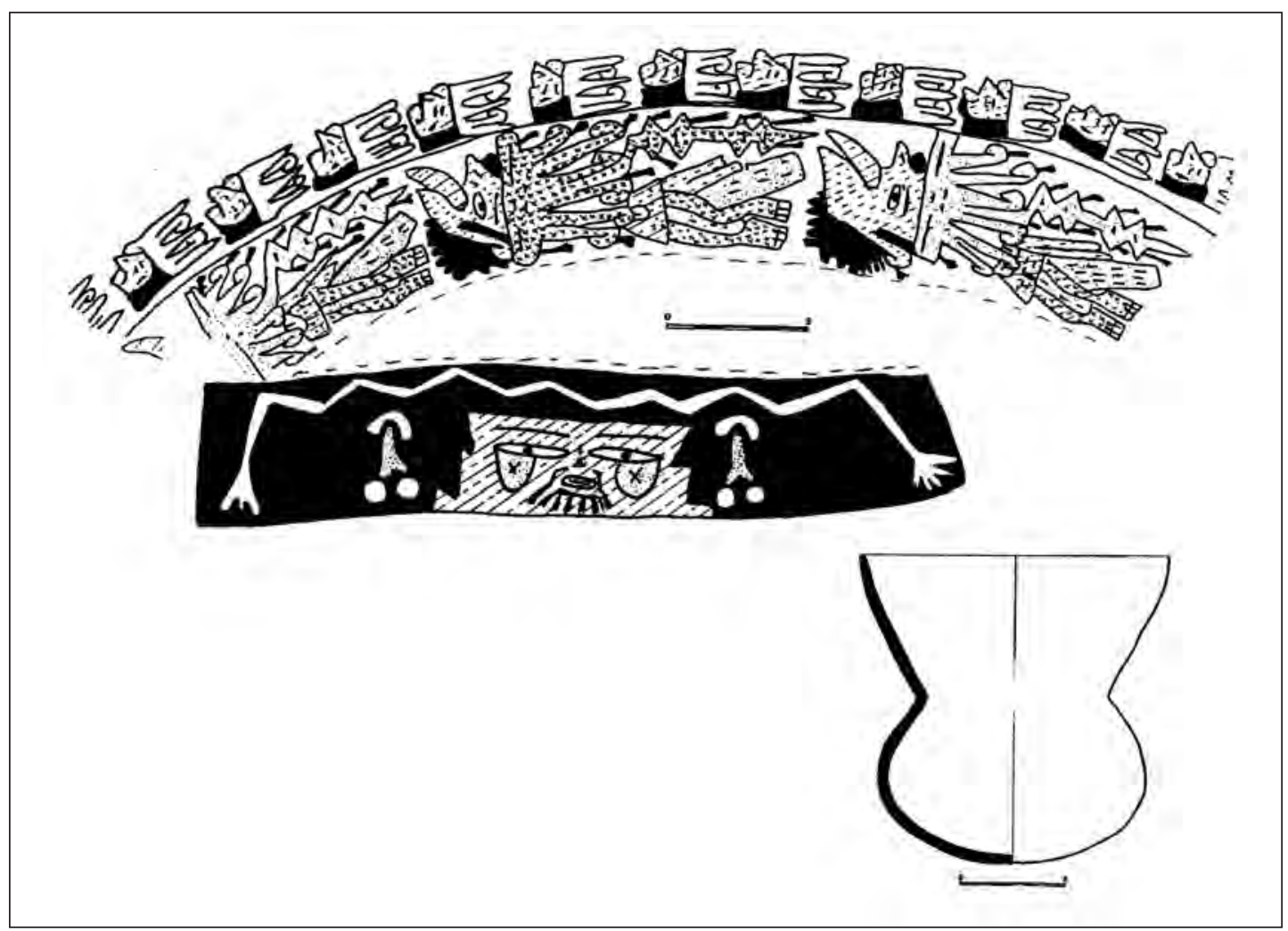

Figura 10

cilmente identificables son las hondas (fig. 10), se trata de un cordel con una ampliación, necesaria para la colocación de una piedra, en la parte central. Así como aparece en las vasijas, se las llevaba enroscadas alrededor de la cabeza. Otras representaciones hacen recordar a redes, tal como se las conoce también de otras esculturas de cuerpo completo, que representan a pescadores. Posiblemente también podrían representar una especie de gorros fabricados de paja que se ha encontrado en entierros. Estas vasijas, por lo menos las siete investigadas, ostentan casi siempre el motivo de ojos de halcón (fig. 11). No parece ser casual esta coincidencia. En comparación, todas las cabezas que llevan la honda en el tocado muestran motivos diferentes en la pintura facial.

Muchas bandas en el tocado ostentan decoraciones geométricas que hacen recordar a sombreros o gorros. Así se representa bandas en espiral, que algunas veces son adornadas con puntos (fig. 12). Se asemejan a los turbantes que se ha encontrado en varios entierros. Otras vasijas muestran rayas verticales o motivos en punta (fig. 13). Estas podrían representar a plumas que se utilizan para adornar la cabeza. También se ha encontrado gorros de paja, los que a su vez estaban adornados con pedazos de textiles; a esto se asemejan las decoraciones geométricas de algunas vasijas. Otras aparecen claramente con un gorro adornado con flecos (fig. 14). En el centro del decorado de algunas vasijas de cabeza trofeo aparece una diadema, con la cual normalmente aparecen los seres de poder antropomorfos. Un gran número muestra decoraciones figurativas, muchas veces se trata de picaflores (fig 15), pero también ranas, hombres, que podrían ser guerreros, divinidades con antifaces, y algunas veces se puede reconocer frutos, plantas, peces y flechas. En las bandas superpuestas que aparecen a partir de la fase 5, las combinaciones de bandas 
ostentan seres antropomorfos con frutos, peces o cabezas trofeo estilizadas, o combinaciones de estos motivos.

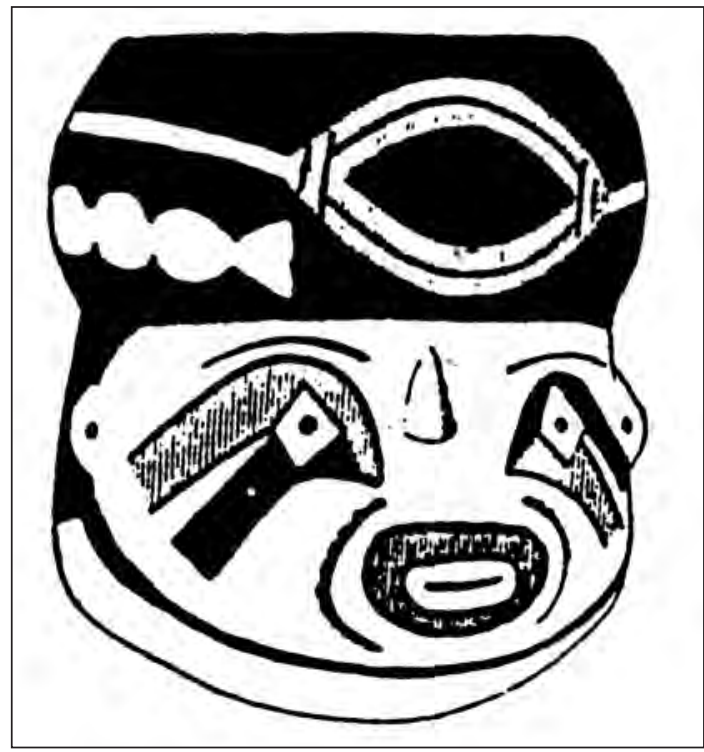

Figura 11

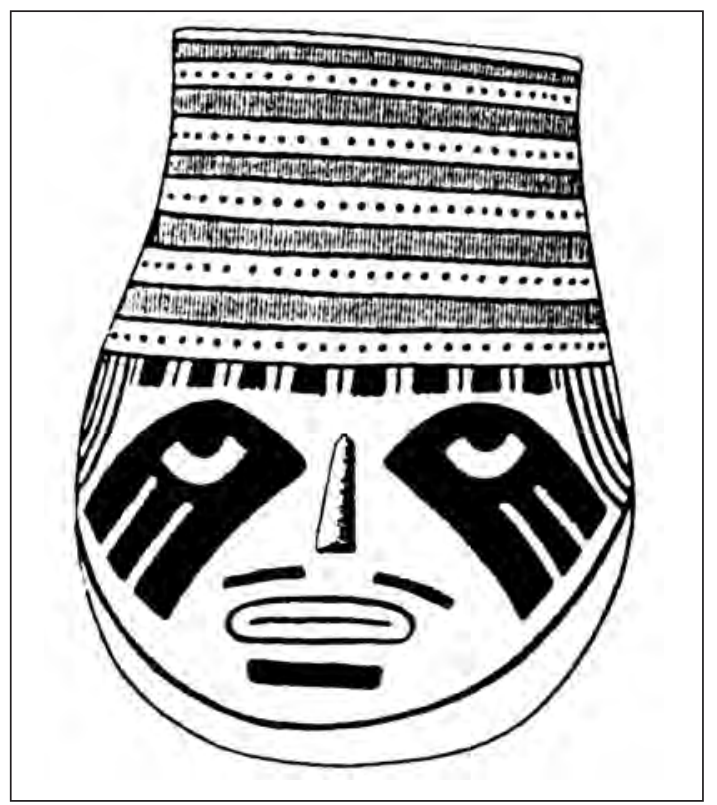

Figura 12
Como los gorros representados se asemejan a los que se conocen de las tumbas, se podría suponer que éstos se relacionan con la función de las vasijas de cabeza trofeo y mostraban motivos de acuerdo a la función.

Un punto frecuentemente discutido acerca de las cabezas trofeo y sus representaciones innumerables es el del significado y la función que estas tenían en la sociedad nasquense. Cultos de cabezas trofeo se conoce de muchas culturas alrededor del globo ${ }^{8}$. Una mirada a estos cultos muestra la gran diversidad de los significados y de la función. Entre los mayas, para quedarnos en un ámbito geográfico cercano, los sacrificios humanos tenían una importancia primordial; en estos las cabezas de los sacrificados recibían un tratamiento especial ${ }^{9}$, ya que, a ellas se atribuía un significado mayor. Probablemente en el núcleo de algunas bolas de caucho que se utilizaba

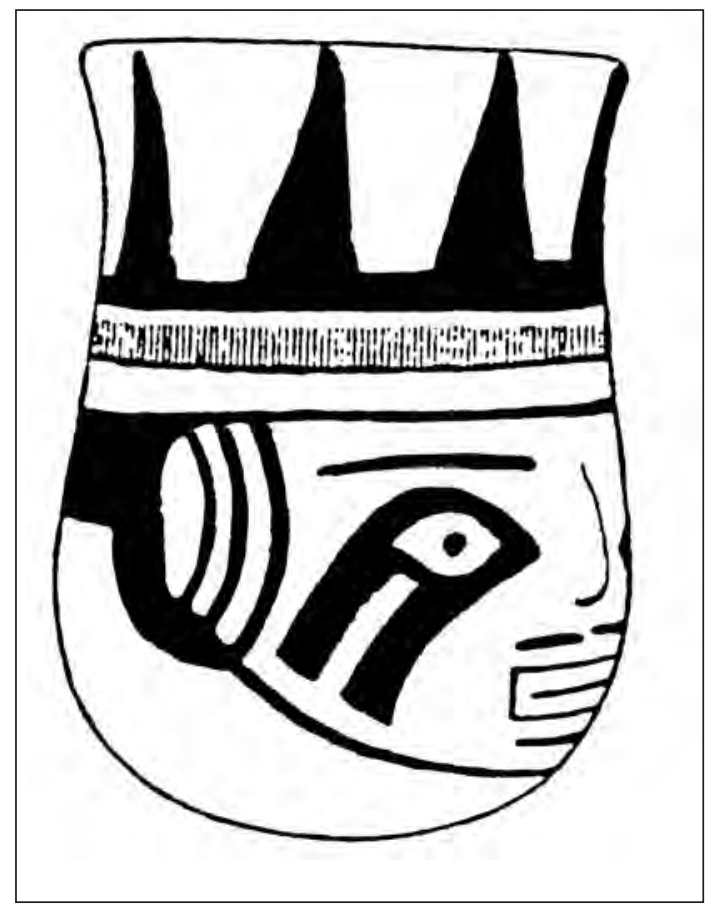

Figura 13

8 Así, por ejemplo, de Indonesia, Borneo, Nueva Guinea, Asia suroriental, América del Sur (Jíbaro, Mundurucú), Mesoamérica (Maya).

9 Los entierros de hombres sacrificados en recintos ceremoniales en realidad eran solamente entierros de cabezas (Helfrich, 1973: 14). 


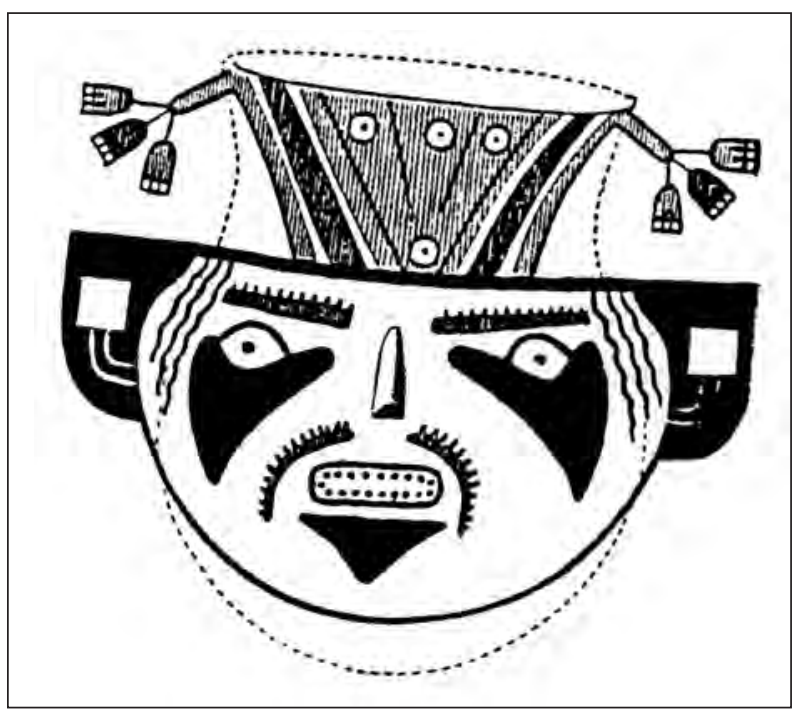

Figura 14

en el juego de pelota se encontraban calaveras humanas ${ }^{10}$. En el Popol Vuh se habla de un juego de pelota con la cabeza de uno de los protagonistas y se relaciona a este hecho con ideas sobre la fertilidad. Ya que también han sido encontradas como sacrificios en construcciones parecerían también estar ligadas a sacrificios propiciatorios en construcciones. Un nuevo gobernante, por ejemplo, tenía que realizar sacrificios humanos en su entronización. Tales rituales tenían para el grupo social en tiempos de inestabilidad política, típica de un cambio dinástico, una función cohesionadora. Al rey le confería además prestigio, simbólicamente demostraba de esta forma su poder. Para poder llevar a cabo tales rituales se organizaba asaltos a ciudades estado vecinas para conseguir, por lo menos durante el período clásico, prisioneros nobles para tales sacrificios. De paso se podía eliminar de esta forma a rivales o intervenir en luchas territoriales ${ }^{11}$.

La caza de cabezas trofeo entre los jíbaros se basaba en otras ideas. Ellos realizaban ata-

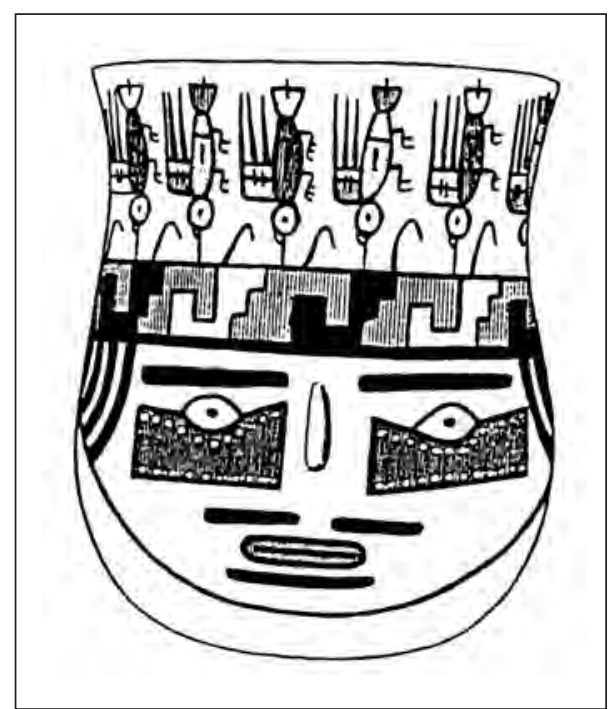

Figura 15

ques a otros grupos para matar a sus enemigos y para apropiarse de sus cabezas. Luchas por el territorio no tenían ninguna importancia en este contexto, ya que, el área habitada por ellos era más que suficiente para su modo de vivir. Muchas veces las luchas se originaban en una venganza. También se salía a realizar un ataque si un hombre soñaba que necesitaba un nuevo alma arutum, o que tenía que reforzar a la que ya tenía. Ambos fines se alcanzaba por la matanza de un enemigo y la preparación de una cabeza trofeo. Detrás de estas costumbres aparece una idea compleja de alma de los jíbaros; de acuerdo a ésta la adquisición de un alma arutum, una de las tres almas, que un humano puede reunir, era especialmente importante para los hombres y les confería invulnerabilidad. La cabeza trofeo era un signo visible de la victoria sobre un enemigo y la posesión de un alma arutum. Resultaba, de esta forma, ser algo como un seguro de vida. A pesar de la existencia de la venganza, la probabilidad de un contraataque se reducía.

10 Esta tesis se basa en el análisis de las escenas de juego de pelota en los paneles del patio correspondiente en Chichén Itzá, en el cual se observa la representación de calaveras como núcleo de las pelotas de caucho (Miller y Houston, 1987: 47ss.).

11 A diferencia de la imagen de los mayas como un pueblo pacífico dedicado a la observación de los astros, ahora se piensa, a partir del desciframiento de su escritura, que su historia estaba marcada por guerras constantes (Freidel 1992: 158ss.). 
Pero en la sociedad de los jíbaros, muy dispersa y acéfala, la importancia de las cabezas trofeo se limitaba al ámbito familiar cercano. Rasgos de ideas relacionadas con la fertilidad se limitaban a las mujeres de los cazadores. Al contrario de la tradición maya, aquí primaba el prestigio del cazador y la cacería tenía un carácter eminentemente individualista. Entre los mayas la importancia ritual era la preponderante, ya que, los sacrificios tenían importancia para toda la sociedad. La adquisición de prestigio del rey visiblemente retrocedía, si bien todavía era parte del significado y no hubiera podido realizarse una entronización sin tales sacrificios.

Estos ejemplos quieren mostrar la complejidad y la variabilidad de las ideas relacionadas con las cabezas trofeo. Sin tradiciones orales o escritas resulta difícil comprender cabalmente la función de las cabezas trofeo en Nasca. A pesar de ello, es posible formular hipótesis a partir de observaciones iconográficas y comparaciones, las que hasta el momento, sin embargo, han conducido a resultados muy contradictorios ${ }^{12}$. Coelho (1972) ha hecho hincapié que las cabezas trofeo de Nasca tienen el carácter de cabezas rituales y no de trofeos para marcar la victoria en una batalla. Silverman (1993: 221) se muestra de acuerdo con esta hipótesis, ya que la preparación pormenorizada de las cabezas podría corroborar un uso fuertemente ritualizado, sin embargo indica, que no se debería buscar una función única, claramente delimitada (1993: 225). Para el período temprano intuye una interrelación entre cabezas trofeo, culto a los ancestros, muerte cíclica, regeneración e ideas de fertilidad. Es que las representaciones de cabezas trofeo dejan percibir por un lado un significado religioso y ritual, ya que, frecuentemente aparecen asociados a los seres antropomorfos y zoomorfos con máscara y diadema ${ }^{13}$. Por otro lado, sin embargo, aparecen en las fases tempranas muchas imágenes, cuya temática central es la fertilidad agrícola, sin duda alguna un tema central para la gente de Nasca. Con la desaparición de Cahuachi como centro religioso, que tuvo una función integradora, se deja percibir un aumento de la cantidad de cabezas trofeo reales. Silverman lo considera una consecuencia de cambios sociales, los que también habrían contribuido a un cambio de función de las cabezas trofeo. En este contexto hay indicios de que en las fases tardías la captura de cabezas trofeo en situaciones bélicas se volvió más importante. No se deja determinar con claridad cual habría sido el carácter de tales confrontaciones. Silverman piensa que tanto problemas territoriales como batallas rituales podrían ser la explicación. Especialmente en los primeros las cabezas trofeo podrían tener en el contexto de la veneración de los antepasados un lugar importante en la legitimación del acceso a la tierra y otros recursos (1993: 25). Para el período tardío Silverman considera posible que las cabezas trofeo también puedan haber sido símbolos de status. Cazadores exitosos hubieran adquirido prestigio y posiciones sociales elevadas.

La cantidad innumerable de cabezas trofeo dejan suponer, que cabezas trofeo reales deben haber tenido una presencia importante en la sociedad Nasca. Pero el número de cabezas trofeo hallado hasta el momento no está de acuerdo con esta suposición. Se puede suponer que las cabezas trofeo por lo menos parcialmente eran de gente nasquense ${ }^{14}$, y que éstas se habían adquirido de manera diversa. Hay cabezas que fueron cortadas del cuerpo en el momento de la muerte de un individuo, y hay otras que recién han sido separadas del cuerpo después de que éste había alcanzado la momificación. Este es otro indicio para pensar en una gama de sig-

12 Tello los consideraba fetiches, imbuidos de poder mágico, que de esta forma tenían influencia sobre la sociedad (1918: 33). Proulx, por otro lado, los entendía como bienes sacrificados para los «seres míticos» representados en la cerámica. Últimamente los relaciona con cultos destinados a incrementar la fertilidad (1999: 86).

13 Silverman los interpreta como «seres míticos» (1993: 221).

14 Carmichael (1988: 183) encontró en los entierros de su muestra 11 \% de esqueletos sin cabeza. En general el asume que los entierros de personas decapitadas en Nasca deben haber alcanzado un 5\%. 
nificados, que no requiere de un modo de obtención singular. La diferencia marcada entre cabezas trofeo reales y la abundancia de representaciones de tales cabezas en la cerámica, deja sospechar que deben haber sido importantes en la cosmovisión de la gente, pero que no era necesario utilizar una cabeza real para cumplir con la función ritual. En vez de las cabezas reales se utilizó símbolos, réplicas en arcilla y las pinturas correspondientes. Sustitutos de este tipo probablemente no son considerados como si tuvieran el mismo poder como las cabezas reales. Pero, quizás comparable a las reliquias y los iconos cristianos, les queda un potencial de poder considerable. Dependiendo del ritual y su significado, y quizás también correspondiente a las personas que lo realizaban, o para las cuales se realizó, se habría utilizado cabezas reales o sus sustitutos simbólicos ${ }^{15}$.

Así que las vasijas de cabezas trofeo habrían sido un sustituto para las reales ${ }^{16}$. Como tales habrían tenido una importancia mayor que las cabezas pintadas, ya que nuevamente hay una diferencia numérica considerable. Mientras las cabezas trofeo reales habrían representado toda la gama de significados atribuidos a ellas, las vasijas escultóricas estarían destinadas a representar un significado simbólico en un contexto ritual. Una excepción serían las vasijas con asa estribo. Son las que más se asemejan a las reales e igualmente han sido encontradas raras veces. Deben haber tenido un uso universal comparable a las reales. Lo mismo podría aplicarse a las vasijas globulares sin gollete.

Las cabezas en forma de vaso se dejan vincular, de acuerdo a las bandas decoradas del tocado, con funciones en rituales específicos que se vinculan con la decoración. Las cabezas que ostentan gorros o tocados, así como se las conoce de esculturas que presentan personajes o de entierros reales (hondas, gorros de paja, turbantes o coronas de plumas) posiblemente se relacionan con un culto a los antepasados. Los emblemas representados identificarían a aquellos. Las vasijas de cabezas decoradas con aves, ranas, peces y motivos de plantas, estarían relacionadas con ideas sobre la fertilidad y los rituales correspondientes.

La importancia creciente de la guerra, de batallas, de violencia en relación con las ideas relacionadas con las cabezas trofeo se refleja en la forma como se pinta los bordes y los cuellos de tales cabezas. Esto es particularmente visible en las vasijas con gollete en forma de embudo. Por un lado se presenta a personajes o seres míticos en batalla, por otro lado los mismos personajes a su vez son representados con una banda de cabezas trofeo estilizadas. Estas vasijas podrían haber tenido una relación con rituales, que estaban vinculados con la cacería de cabezas trofeo o actividades bélicas que proporcionaban la oportunidad de obtener y preparar tales cabezas.

Considerando a las vasijas que representan cabezas trofeo como sustituto de las reales se puede indagar en la gama de significados, y sus cambios, que éstas tenían para la gente de Nasca.

15 No pocas cabezas trofeo se encontró en acumulaciones mayores (Browne, García y Silverman, 1993). Tales depósitos de vasijas de cabezas trofeo no se conoce, mientras sí se ha hallado tanto las cabezas como vasijas en entierros, en los cuales parecen haber tenido el mismo significado simbólico.

16 Esto no se debe confundir con la idea errónea que las vasijas de cabezas serian un sustituto de una cabeza que falta en un entierro. Esta idea se había generalizado después de que Kroeber encontró un cuerpo decapitado en Aja B, en el cual en vez de la cabeza se encontró una vasija. Carmichael (1988: 314) ha investigado el material de las excavaciones de Kroeber y encontró que en 16 tumbas se había encontrado vasijas de cabezas trofeo, pero que solo en dos se trataba de entierros de personas decapitadas. En uno de los casos la cabeza había sido sustituida por una vasija correspondiente, en el otro se había puesto una calabaza a manera de reemplazo. 


\section{BibLIOGRAFía}

Blasco Bosqued, C. \& Ramos Gomez, L. J.

1986 Catálogo de la Cerámica Nasca. Vol. 1. Madrid

1980 Cerámica Nasca. Valladolid

Browne, D.; García, R. \& Silverman, Helaine

1993 A Cache of 48 Nasca-Trophy-Heads from Cerro Carapo, Peru. Latin American Antiquity. 4(3): 274-294

Carmichael, Patrick H.

1988 Nasca Mortuary Customs: Death and ancient society on the south coast of Peru. Calgary

Coelho, Vera P.

1972 Enterramentos de Cabecas da Cultura Nasca. Ph.D.diss., University of São Paulo, Brazil

Freidel, David A.

1992 Krieg - Mythos und Realität. Die Welt der Maya. Hildesheim/Mainz

Harner, Michael J.

1984 The Jivaro. People of the sacred Waterfalls. Los Angeles/London

Helfrich, Klaus

1973 Menschenopfer und Tötungsrituale im Kult der Maya. Monumenta americana IX Berlin

Kroeber, Alfred \& Collier, Donald

1998 The Archaeology and Pottery of Nazca. Peru. M. Carmichael (Ed.) Chicago

Miller, Mary \& Houston, Stephen

1987 The classic Maya ballgame and its architectural setting - A study of relations between text and image. RES 14/:47-65

Proulx, Donald

1999 Kopfjagd und rituelle Verwendung von Trophäenköpfen in der NascaKultur. Nasca - Geheimnisvolle Zeichen im Alten Peru. Zürich: 79-88

1968 Local Differences and Time Differences in Nasca Pottery. University of $\mathrm{Ca}$ lifornia Publications in Anthropology 5. Berkley
Sawyer, Allan

1954 The Nathan Cummings Collection of Ancient Peruvian Art. Chicago

Schlesier, K.h.

1959 Stilgeschichtliche Einordnung der Nasca-Vasenmalereien. Ein Beitrag zur Geschichte des vorkolumbischen Peru. Vaticanstadt

Seler, Eduard

1961 Gesammelte Abhandlungen zur Amerikanischen Sprach- und Altertumskunde. Graz

Silverman, Helaine

1993 Cahuachi in the Ancient Nasca-World. Iowa

Tello, Julio C.

1918 El uso de las Cabezas Humanas artificialmente momificadas y su representa-

Uhle, Max ción en el antiguo arte peruano. Lima

1901 Die deformierten Köpfe von peruanischen Mumien und die Uta-Krankheit. Verhandlungen der Berliner Gesellschaft für Anthropologie, Ethnologie und Urgeschichte. Jahrgang 33:404-408 